\title{
Las fronteras de la
} publicidad televisada en la era de conexión The boundaries of television advertising in the age of connection

Adriana Pierre Coca ${ }^{1}$

Alexandre Tadeu dos Santos ${ }^{2}$

\footnotetext{
${ }^{1}$ Doutora em Comunicação e Informação na Universidade Federal do Rio Grande do Sul (UFRGS). Integra o grupo de pesquisa - Gpesc Semiótica e Culturas da Comunicação (UFRGS). É autora do livro Tecendo rupturas - o processo da recriação televisual de Dom Casmurro (Rio de Janeiro: Tríbia, 2015) e atua principalmente nas pesquisas sobre os aspectos teóricos e metodológicos das rupturas de sentidos na teledramaturgia contemporânea pelo viés da Semiótica da Cultura. E-mail: pierrecoca@hotmail.com

${ }^{2}$ Professor da Universidade Federal de Goiás e doutor em Ciências da Comunicação pela ECA-USP. E-mail: alexandresantos5@terra.com.br
} 
Resumen: la reflexión piensa las fronteras entre la internet y la publicidad televisada y tiene como enfoque teórico y metodológico la Semiótica de la Cultura, con la discusión basada en el concepto de frontera propuesto por Lotman (1999) y las incursiones de los autores Jenkins et al. (2014) y Manovich (2005) sobre la era de la conexión de la cultura, así como los apuntes de Machado A. (2011) sobre el audiovisual. Nos importa el diálogo y las intersecciones entre los diferentes sistemas de signos, pues creemos que así como la internet transforma la manera de producir la publicidad, al mismo tiempo se sobrepone a ella.

Palabras clave: semiótica de la cultura; publicidad televisada; era de la conexión; fronteras.

Abstract: this reflection considers the boundaries between the Internet and televised advertising, using the Semiotics of Culture as the theoretical and methodological approach. The discussion is based on the concept of boundary proposed by Lotman (1999) and on discussions made by Jenkins et al. (2014) and Manovich (2005) on the era of the connection of culture, as well as the notes made by Machado A. (2011) on the audiovisual. We focus on the dialogue and the intersections between the different sign systems due to believing that as the Internet transformed the way advertising is produced, at the same time the internet also overlaps with it.

Keywords: semiotics of culture; television advertising; connection age; boundary. 


\section{Introducción: el contexto del objeto}

Esta reflexión trata de las fronteras entre lenguajes en la publicidad televisual. El principal aporte teórico-metodológico adoptado es la semiótica de la cultura, con la discusión basada en el concepto de frontera propuesto por Iuri M. Lotman (1999) y de la Cultura de la Conexión investigada por Jenkins et al. (2014). Este texto se propone a pensar como se despliegan los diálogos y las intersecciones entre los diferentes sistemas de signos, sobre todo la publicidad televisual con relación a las "nuevas medias" en el actual contexto de la convergencia mediática. Nuestra principal preocupación es observar los tensionamientos que provienen de este proceso que nos hacen percibir determinados sistemas culturales que componen la semiosfera pensada por Lotman (1999). Creemos que, de manera recurrente, la publicidad televisual se sobrepone a la producción de video en internet, así como la internet por medio de los virales, por ejemplo, interfiere en la creación publicitaria vehiculada en la televisión, que es un medio tradicional.

Para tanto, organizamos esta reflexión en cuatro momentos: el contexto del objeto, que es esa parte, la articulación de las premisas teóricas que introducen el concepto de frontera y de la cultura de la conexión, y los análisis puntuales sobre las piezas audiovisuales publicitarias seleccionadas como corpus para la investigación a la luz del concepto de frontera de Lotman (1999) y sobre las incursiones de los autores Jenkins et al. (2014) sobre la llamada cultura de la conexión, que nos auxilian a comprender la comunicación contemporánea. Y, por fin, tejimos las consideraciones finales.

En esta búsqueda, el cuestionamiento que se impone es, ¿cómo se están concretando las reconfiguraciones de la publicidad televisual en la contemporaneidad, en la era de la cultura de la conexión? Asumimos que vivimos hoy la era de la cultura de la conexión porque estamos en sintonía con la reflexión de Jenkins et al. (2014), que defiende que este momento ya avanzó con relación a la era de la cultura de la convergencia mediática, muy bien definida y argumentada por Jenkins (2009) a mediados de los años 2000.

Jenkins nos aclara que el término Cultura de la Conexión trata de las múltiples maneras de circulación de contenido en la era digital. Desde hace un tiempo, no muy distante, en la era de la cultura de masa y de las medias, todo el contenido producido por las medias tradicionales (televisión, radio, cine, industria fonográfica) era controlado y distribuido por estos propios medios representados por grandes organizaciones. En ese periodo, el éxito de los contenidos producidos por los medios tradicionales siempre ha sido medido por la cantidad de personas que 
organizaban sus horarios para acompañar, por ejemplo, un programa de televisión, y literalmente se "pegaban" a la pantalla y el contenido visto se propagaba por los comentarios boca en boca que originaban a partir de entonces. A mediados de los años 90, con el surgimiento de la televisión por cable y el uso más efectivo de internet que comenzaba a popularizarse entre los usuarios en Brasil, el espectador pasó a contar con más variedades de oferta de programación, siendo testigo de una revolución que se intensificaría a partir de ahí: la reivindicación de una participación más activa en los procesos de producción y circulación de contenidos, un fenómeno acuñado por Jenkins (2009) como Cultura de la Participación. De ese modo, contenidos que anteriormente se distribuían por los medios de comunicación pasaron a circular por la red, a través de la compartición de informaciones.

Por cuenta de las proposiciones delineadas arriba, definimos como objeto empírico tres trabajos que reflejan con claridad cómo vienen sucediendo los cambios en la producción y distribución de la publicidad televisual inmersa en la comunicación digital. Son: (1) Uno de los comerciales que anunció el Gran Premio de Brasil de Fórmula 1, de TV Globo, en 2014, que reproduce la narración del niño Leandro de 9 años que tuvo mucho éxito meses antes, después de publicar en el sitio de videos YouTube; (2) un comercial del Banco Itaú vehiculado en Brasil en 2012 que tuvo como personaje principal un bebé estadounidense cuyas carcajadas se replicaron y compartieron en las redes sociales por todo el mundo; y (3) la entradilla de programación de la red de televisión por cable TNT, intitulada de A dramatic surprise on a quiet square, que pone en diálogo los lenguajes cinematográfico y publicitario en un espacio de exhibición relativamente "nuevo" que es la internet.

Para finalizar la primera parte de esta introducción, aún se hace necesario ubicar el ambiente de dichas piezas publicitarias para la comprensión de cómo pueden haber sido producidas y propagadas. Para tanto, recurrimos a las investigaciones de otros autores, que son importantes en esa contextualización, aunque complementarios en este artículo. Dicho planteamiento ya se hizo por nosotros en otros trabajos, y por eso hacemos uso de la autocitación en los trechos a continuación.

Con el avance de la internet, sobre todo la cuestión de las redes sociales, como Facebook y Twitter, la televisión estuvo obligada a llevar a cabo estrategias conjuntas con otros medios de manera más intensa, un reflejo del momento de profundas transformaciones socioculturales que algunos investigadores nombran cultura digital, otros cibercultura (COCA; SANTOS, 2014). Santaella (2003) considera el rápido desarrollo de la multimedia uno de los aspectos más significativos de la evolución digital, porque la multimedia une las principales formas de 
comunicación: la escritura, la audiovisual, las telecomunicaciones y la informática. La internet es multimedia y la principal representante de las llamadas "nuevas medias". En las palabras de Lev Manovich,

las nuevas medias son objetos culturales que usan la tecnología computacional digital para distribución y exposición. Por lo tanto, la internet, los sitios, la multimedia de computadoras, los juegos de computadoras, los CD-ROMs y el DVD, la realidad virtual y los efectos especiales generados por computadora se encuadran todos en las nuevas medias. (2005, p. 27)

Dichas "nuevas medias" permitieron la multiplicación en los modos de accesibilidad, aun así la televisión no desapareció con los acelerados cambios provocados por la era digital, tampoco da señales de un futuro sombrío en los próximos tiempos. Sin embargo, ha sido necesario adaptar las nuevas exigencias del mercado y del público, que pasó a ser también un usuario, más allá de consumidor de estas múltiples pantallas.

Entendemos que el pasaje de una era cultural a otra no es linear, hay una superposición "creando tejidos culturales híbridos y cada vez más densos" (SANTAELLA, 2003, p. 81). Según Santaella (2003), son seis eras culturales bien definidas: oral, escrita, impresa, de masas, de las medias y digital. La superposición a que se refiere la autora se puede ver como la convergencia de los medios, que no es reciente. Sin embargo, la superposición entre los lenguajes nunca ha sido tan veloz y acentuada. "En realidad, la convergencia siempre ha sido esencial a la evolución y al proceso mediamórfico" (FIDLER, 1997, p. 63). Roger Fidler (1997) llama mediamorfosis al proceso de modificación de un medio, cuando uno nuevo nace y ambos se auto influyen, el medio antiguo pasa a evolucionar de otra forma para no morir. En el momento de su origen, esta media, que después de algún tiempo gana aires de obsoleta, señala en verdad una intensa transformación.

Para comprender los despliegues que antecedieron la actual lógica de la convergencia mediática, recurrimos a Arlindo Machado para trazar un breve histórico sobre la convergencia y la divergencia de las artes y de los medios. Machado A. (2010) usa la metáfora de los círculos con núcleos duros para pensar las especificidades de cada lenguaje. Entre las décadas de 1950 y 1980 era mucho más fácil discernir cada medio "en función de su especificidad” (2010, p. 60). En esa época, no había, de manera evidente, el intercambio de experiencias entre los productores de cine, video, televisión y fotografía, aunque la aproximación entre los lenguajes sea innegable desde los primordios de cada una. En el fin de los años 1980, ya llegaba el momento 
en que se volvía imposible no asumir el hecho de que culturas y lenguajes se mezclan y de que “(...) los procesos de hibridación pueden favorecer una convivencia más pacífica entre las diferencias" (MACHADO A., 2010, p. 64).

De ese periodo en adelante, ejemplos en las artes y en los medios de comunicación comenzaron a dar señales de una convivencia pacífica, a punto de que algunos contenidos presentaban un tipo de hibridación que vuelve casi indisociable la distinción entre lenguajes. Machado A., en el libro Pré-cinemas ๒ pós-cinemas, usa la expresión “mestizaje de las imágenes" (MACHADO A., 2011, p. 216) para hablar del proceso de configuración híbrida que involucra un flujo de imágenes superpuestas que exige del receptor reflejos rápidos para aprehender las conexiones. "Las imágenes están compuestas ahora con base en fuentes las más diversas: parte es fotografía, parte es diseño, parte es video, parte es texto producido por generadores de caracteres y parte es modelo generado en computadora" (MACHADO A., 2011, p. 216).

Es a partir de este contexto que parten nuestras observaciones sobre los remodelados en la publicidad televisual en la era de la conexión. Lanzamos a partir de este punto las bases teóricas que se presentarán y articularán, y, a continuación, el análisis de las piezas publicitarias propiamente dichas, encerrando con los resultados parciales, aún preliminares de esta investigación.

\section{Articulación de las premisas teóricas}

Iniciamos la discusión sobre los pilares teóricos que basan esta investigación, presentando los conceptos que fundaron la Semiótica de la Cultura (SC). La semiótica de la cultura es una disciplina teórica que surge con la necesidad de comprender la construcción de la cultura y tiene como objeto de investigación los sistemas semióticos. La SC se constituye en el departamento de semiótica de la Universidad de Tártu, en Estonia, durante los años 1960, principalmente a partir de los encuentros de verano. Es en dicho contexto que la comunicación pasa a hacer parte de los intereses de los investigadores de Tártu-Moscú, entre ellos Iuri M. Lotman, uno de los principales representantes de esa perspectiva teórica que es también uno de los autores clave de esta reflexión.

Uno de los conceptos importantes para Lotman (2003) es el de texto/lenguaje visto como un generador de significados, que asume una función comunicativa al dar una información al receptor. Para Lotman, ese mismo texto puede tener también otra función, más allá de esa, que es la función creativa. El autor reitera que "En esta función, el texto no aparece más como un mero envoltorio pasivo del significado determinado de antemano, sino como generador de significados" (2003, p. 2). El 
texto presenta, aún, una tercera función que está vinculada a la memoria de la cultura y refleja un pasado cultural, por lo tanto, está arraigada por la memoria de otros textos que forman la historia de la cultura humana. De ese modo, una obra de arte se puede presentar como un sistema sígnico complejo y un espectáculo de danza, una película, una catedral o un poema también son textos que se pueden "leer".

En esa perspectiva, podemos entender de manera simplificada que el texto de la publicidad televisual, por su naturaleza intrínseca, ya es un texto comunicativo y que puede ser también creativo. El texto publicitario televisual se constituye como una amalgama de varios otros textos que abarca lo sonoro, lo verbal, lo corporal y, según reflexiona Lotman (2003), también viene impregnado por memorias, un conjunto de signos en relación que producen significados. Sin embargo, reforzamos que todos los textos tienen sus especificidades, que generan nuevos sentidos de manera distinta para cada receptor. Irene Machado reitera diciendo que el texto pensado por SC "no es constituido como unidad verbal de una lengua, sino un texto poliglota, con múltiples tramas y generador de nuevos textos como trabajo entre sistemas de signos que actúan, interactúan y reaccionan unos con otros [...]." (2015, p. 14-15). De esta forma, un mecanismo en constante recodificación de los lenguajes $\mathrm{y}$, consecuentemente, de la cultura.

Dicho esto, es posible comprender como Lotman (1999) piensa la cultura. Según el autor, la cultura es un texto complejo, una trama intrincada, un dispositivo pensante, que detiene la memoria colectiva y tiene dinamicidad, una vez que está en continuo proceso de transformación, desencadenado por tensionamientos. Nosotros nos reconstruimos porque estamos vinculados a esa inmensa red de significación, que contempla textos dentro de textos. De ese modo, se evidencia que el interés de la Semiótica de la Cultura son las relaciones entre los textos, que se desencadenan en un espacio semiótico, una dimensión abstracta a la cual Lotman (1996) denominó semiosfera³.

En ese espacio en que ocurren las semioses se relacionan diversos textos, códigos y también sistemas delimitados por fronteras, líneas imaginarias, sujetas a “contaminaciones", es decir, interferencia de otros sistemas, ya que la frontera es

\footnotetext{
${ }_{3}^{3}$ En el texto de introducción del libro Cultura y explosión (1999), Jorge Lozano explica que el concepto de semiosfera tiene inspiración en el término biosfera propuesto por el biogeoquímico ruso Vernadski. Según el autor, dicha reflexión puede haber inspirado a Lotman: "se sustituye la noción de adaptación por la de construcción, lo que permite poner en evidencia como los organismos conducen su propia organización interna eligiendo las piezas y fragmentos del mundo externo relevantes para su existencia, alteran la escena en que viven, alterando la estructura física". LOZANO, Jorge. Prefacio In: LOTMAN, Iuri. Cultura y explosión.
} 
móvil y maleable. Por eso, en esa red textual compleja, la frontera tiene un aspecto fundamental (ROSÁRIO; AGUIAR, 2014).

El concepto de frontera está formulado a partir de una noción matemática, Lotman aclara: "un conjunto de puntos pertenecientes simultáneamente al espacio interior y al espacio exterior" (1996, p. 24). Ampliando esa cuestión, lo que de hecho se establece es que la información externa al espacio de la semiosfera solo se incorpora después que se traduce, es decir, debe haber una semiotización que transformará el no-texto en texto.

Eso no indica, sin embargo, que hay una oposición entre lo que hace parte de la cultura y lo que está fuera, pero evoca una disputa que podemos comprender como saludable entre esos textos, lenguajes y códigos. Por ejemplo, cuando hay una no coincidencia de códigos, que ocurre en cierta medida cuando el lenguaje de la internet se mezcla a la de la publicidad televisual y desencadena una reconfiguración del sistema, en el caso del lenguaje publicitario en la televisión, eso se concreta porque ese choque teje un nuevo texto, es un acto cultural creador, un avance en el desarrollo de dicho lenguaje (LOTMAN, 1998).

La cultura solo se realiza en el lenguaje, en la tesitura de lenguajes, capaz de generar significación, y lo que faz parte de la cultura está en constante relación con lo que es extralingüístico, que está fuera del lenguaje el cual dominamos. Es en ese imbricamiento que se despliegan los tensionamientos entre textos, códigos y sistemas diversos. Algunos van a ocupar el centro de la semiosfera, que son los dominantes, más rígidos de ser interpenetrados, y otros se concentran en la periferia de la semiosfera, pudiendo cambiar de lugar dependiendo de las relaciones establecidas. Esos sistemas se pueden ir integrando y diluyendo unos en otros y sufrir cambios imprevisibles, asumiendo nuevas configuraciones (LOTMAN, 1999).

Metafóricamente, podemos pensar en esferas de lenguajes (sistemas de signos) que se intersecan y, al chocarse, surge una zona de tensión; en esa relación se establece la comunicación, pero hay también momentos de intraducibilidad. Es con los tensionamientos que nuevos sentidos se pueden generar, momentos en que el lenguaje asume la función creativa. Estamos produciendo semiosis al vivenciar esos procesos de traductibilidad e intraducibilidad, y es cuando el grado de tensión alcanza niveles elevados que los códigos se desterritorializan y surge el nuevo (LOTMAN, 1999).

En esa vía, observamos como algunas piezas publicitarias exhibidas en la televisión pasan a presentar ese momento de rupturas de sentidos, es decir, presentan algún elemento que no concuerda con el sistema hegemónico (lo que es esperado) y ofrece al espectador, algo que lo tensiona, inquieta. 
Reflexionando sobre la publicidad televisual podemos decir que al incorporar elementos ajenos a sus cánones, como aspectos propios del lenguaje de la internet y poco probados en la televisión, o aún de otros lenguajes como el teatro, el cine, el comercial de televisión gana nuevos matices, desterritorializa sus códigos y crea un nuevo texto para la publicidad contemporánea. Lo que es sano, porque este es el movimiento de los sistemas de la cultura.

$\mathrm{Y}$ ese movimiento solo se realiza porque las fronteras son tenues y penetrables, están susceptibles a las intersecciones y captación de informaciones de otros lenguajes, y dependen de eso para su supervivencia y reconfiguración.

Tradicionalmente pensada para circular en la programación de la televisión en formatos limitados a la duración temporal de 30 segundos, 45 o hasta 1 minuto, el comercial de televisión fue, durante décadas, el protagonista de los intervalos comerciales anunciando productos, ideas y servicios y preveía un espectador pasivo, acostumbrado a adaptarse a la programación ofrecida por las grandes redes de televisión. A partir de ese punto, nos dedicamos a reflexionar sobre esta televisión impactada por un mundo cada vez más tecnológico y digital, en el cual la Cultura de la convergencia y la transmedialización impulsan profundas transformaciones en los modos de producir y consumir televisión.

La expresión fin de la televisión se refiere, de un modo general, a los cambios de producción y consumo que el vehículo viene probando en la contemporaneidad. La televisión pasa por momentos de profunda transformación formal y nuestra reflexión suscita señalar como se viene desarrollando este diálogo con las nuevas formas de visibilidades surgidas con la internet.

En el inicio de los años 90, el surgimiento de hecho de la televisión por cable y por suscripción y el uso ampliado del espectro de frecuencia de transmisión UHF hicieron factible el nacimiento de nuevas emisoras de televisión como MTV Brasil. Este momento representa una fase del vehículo en la cual se verifica una ampliación en las posibilidades de oferta y consumo de programas televisivos. Aún con el aumento de la oferta de la programación, la fuente emisora comandaba la recepción a través de programación que obligaba la audiencia a acompañar las producciones en horarios preestablecidos.

La gran novedad, sin embargo, aún estaba por surgir, ya en los años 2000, con las grandes transformaciones tecnológicas del campo de la informática que posibilitaron la gran revolución digital. Todas estas transformaciones hacen con que partamos de la hipótesis de que estamos en una era Post TV (CARLÓN, 2014), caracterizada por un puntual cambio en la relación de consumo: si anteriormente 
era la emisora que comandaba la recepción, pues preveía un espectador pasivo (JENKINS, 2009), actualmente el consumo programa la recepción, a través de un consumidor activo que consume cuando, como y donde quiere acompañar determinado programa. En esa perspectiva, Carlón nos llama la atención para una de las principales características de la Post TV: la televisión expandida. Se trata de un fenómeno que afecta directamente los mecanismos de producción de la televisión, en la medida en que la obliga a pensar en un nuevo tipo de espectador acostumbrado a recibir mensajes en diversos "dispositivos mediáticos (teléfonos, celulares, notebooks, etc.) y medias (como el YouTube, Terra, etc.)" (CARLÓN, 2014, p. 19).

Atento a la paulatina caída de audiencia que la televisión tradicional se enfrenta año tras año, y la constatación de que el público consume contenidos de televisión en diversas pantallas, el $\mathrm{Obitel}^{4}$ aclara que:

Lo que quedó claro en 2014 es que esta migración, en general, está teniendo un fuerte impacto en las mediciones de rating y share, ya que la mayoría de los países registra una reducción en sus niveles de audiencia, pues la forma tradicional de ver televisión se está abandonando, principalmente por los jóvenes, lo que no significa que no siguen viendo programas televisivos. Ellos miran televisión, pero en otro tipo de dispositivos o por medio de plataformas de Video on Demand (VoD), por ejemplo, Netflix o Claro Video. Eso está sucediendo no solo en los países que hacen parte del Obitel, sino que es un fenómeno mundial. (LOPES; GÓMEZ, 2014 p. 29)

Resumidamente: la reflexión hasta este punto del artículo señala cómo la frontera entre la media televisual y la publicidad en ella vehiculada también están inmersas y se transforman ante las nuevas tecnologías de comunicación y así, como indica Lotman (1999), son sistemas que se intersecan y al transformarse desencadenan un nuevo sistema, ahora con elementos que no les pertenecían, pero que, por su vez, rompieron las tenues fronteras del lenguaje, y de esa forma aseguran la dinámica de la cultura.

\footnotetext{
${ }^{4}$ Observatorio Iberoamericano de Ficción Televisiva que reúne equipos de investigadores de Argentina, Brasil, Chile, España, Estados Unidos, México, Venezuela, Colombia, Ecuador, Perú, Portugal y Uruguay, con el objetivo de monitorear datos cuantitativos y cualitativos sobre la producción y exhibición de ficción televisiva en esos países.
} 


\section{Tejer los análisis}

Así expuesto, reiteramos que la televisión se encuentra en una nueva era que se caracteriza por profundos cambios en el proceso de producción y consumo de productos audiovisuales. Como afirma Jenkins, los consumidores no desempeñan más el papel de simples espectadores pasivos, al contrario, reivindican un papel más activo en ese proceso de producción. En esa perspectiva, plataformas como el YouTube son emblemáticas, pues permiten que el usuario produzca sus propios contenidos y vehicule videos para un amplio público a través de la internet. El éxito de un video se mide por la cantidad de visualizaciones, cuanto más se propaga más comparticiones y comentarios se llevan a cabo. No se puede determinar con claridad lo que hace con un video tenga éxito en internet, sin embargo, es un contenido que "se pega" y con alto potencial de propagabilidad:

La propagabilidad se refiere a recursos técnicos que vuelven más fácil la circulación de algún tipo de contenido en comparación con otros, a las estructuras económicas que sostienen o restringen la circulación, a los atributos de un texto de media que pueden despertar motivación de una comunidad para compartir material y a las redes sociales que conectan las personas por medio del intercambio de bytes significativos. (JENKINS et al., 2014, p. 26)

Llama la atención el video intitulado “Taca-le pau”. Un fenómeno de “propagabilidad” en la internet en 2014. Se trata de una grabación de 26 segundos de dos primos jugando, el adolescente Marcos de 12 años baja una carretera de tierra con un goitibera (carrilana) y el primo más joven, Leandro, narra el hecho. Lo que llamó la atención de los internautas fue la entusiasmada narración que decía: "Allá viene Marcos bajando el cerro de la Abuela Salvelina. "Taca-le pau” (métele) en ese carrito, Marcos. "Taca-le pau” (métele) Marcos. "Taca-le pau, taca-le pau, taca-le pau. Allá va (Bien), Marcos viejo"5. El video ha sido rodado en la pequeña ciudad de Vale do Itajaí, Taió, en Santa Catarina, región sur de Brasil, y enseguida pasó a ser compartido por las redes sociales y se volvió un viral en Twitter. Además de atraer miles de seguidores en una fampage propia y servir como inspiración a innúmeros memes en Facebook, el niño Leandro también conquistó el puesto de narrador de los comerciales de GP de Brasil de 2014; en la voz de él, uno de los comerciales

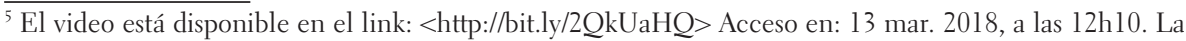
publicación se hizo en 1 enero de 2014, tuvo repercusión meses después y un año más tarde, cuando realizamos este último acceso contaba con cerca de siete millones de visualizaciones en YouTube.
} 
vehiculados en TV Globo ${ }^{6}$, con duración de 30 segundos, tuve la siguiente narración: “Puedes venir, Nico (Nico Rosberg, piloto alemán). Allá viene Hamilton (Lewis Hamilton, piloto británico), bajando el cerro de la S de Senna. ¡Taca-le pau (métele) en ese carrito, Hamilton! Taca-le pau (métele) Alonso (Fernando Alonso, piloto español). Taca-le pau, taca-le pau". En ese momento, el locutor anuncia: "Ahí viene el gran premio Petrobras de Brasil de Fórmula 1, el 7, 8 y 9 de noviembre en el autódromo de Interlagos, acceda gpbrasil.com.br y garantice ya su entrada y descubra la emoción de estar ahí”. Y la voz Leandro finaliza: “Taca-le pau Massa... taca-le pau". Este es un ejemplo evidente de cómo las fronteras entre los diferentes lenguajes del vasto sistema comunicacional de nuestros días se diluyen, sobreponen y se influencian mutuamente. Jenkins nos llama la atención para el concepto utilizado en el área de marketing con el objetivo de comprender el éxito de un determinado comercio on-line. Se trata de la "adherencia" que "se refiere a la necesidad de crear un contenido que atraiga la atención de la audiencia y que la involucre" (JENKINS et al., 2014, p.26). Evidentemente, la media tradicional, representada por la televisión, reconoció el éxito del pequeño video casero y buscó aprovechar la "adherencia” de ese contenido y de su alto potencial de "propagabilidad", es decir, su probable poder de compartición en diversas otras plataformas como Twitter, Facebook, YouTube, entre otros más. Es una clara señal de que la televisión pasa por un periodo de transición y “sería un cambio en esa dimensión que podría significar no propiamente un fin de la televisión, sino el inicio de otro contrato paralelo y, especialmente, el surgimiento de otros tipos de reconocimiento y comportamiento del público televisivo en escenarios digitales." (OROZCO, 2014, p. 101). Cuando Orozco habla en cambio y con eso establece un contrato paralelo, está reflexionando cómo ese movimiento engendra el modo como la compleja tesitura cultural, según SC, se reconstruye con los lenguajes impactados por las rupturas de las fronteras y la cuestión de los intercambios entre sistemas diversos para que cambien y se renueven.

El segundo ejemplo que observamos es un video que se propagó en internet y tiene como protagonista un bebé de Saint Louis, Missouri, Estados Unidos. El video surgió de una broma, en la cual el padre del niño, desempleado, había recibido una carta más de rechazo para un empleo. En entrevista al periódico Folha de São Paulo, el padre afirma que "cuando yo la rompí por la mitad, el pequeño Micah comenzó a reírse histéricamente. Fue la primera vez que se rió con un papel rompiéndose, pero

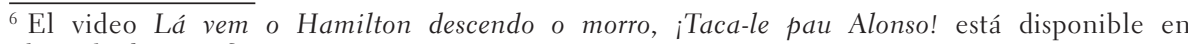
$<$ http://bit.ly/2sgs7jf >. Acceso en: 13 mar. 2018. 
siempre tuvo aquella risa deliciosa. Entonces tomé la cámara y comencé a filmarme a mí rompiendo las cartas y otros folletos que llegaron para que yo pudiera mostrarle a mi mujer cuando llegara del trabajo". ${ }^{7}$ El padre cuenta aún que tiempos después una agencia de publicidad brasileña lo contactó explicando el concepto de la campaña y que le gustaría usar las imágenes originales del video en un comercial de televisión para un banco brasileño.

El banco en cuestión es Itaú-Unibanco, considerado el mayor banco privado de Brasil. Con una edición de las imágenes originales de internet, el comercial de Itaú, con duración de 30 segundos, ha sido vehiculado en el prime time de las grandes redes de televisión brasileñas durante el año de 2012. La productora de video ciertamente tuvo poco trabajo de producción, una vez que el video llegó para la edición prácticamente pronto y realizado, probablemente, por una cámara de video no profesional. Un cambio de paradigma en la producción publicitaria televisual que, tradicionalmente, siempre primó por el alto patrón de calidad de imagen. Prueba de que el contenido generado por el usuario y con alto potencial de "propagabilidad" es muy importante y puede sobreponerse a las tradicionales técnicas y patrones de producción televisuales. En la campaña, la siguiente narración ha sido insertada en las imágenes: “¿sabes el extracto mensual en su cuenta de Itaú?”, (papeles se rompen y el bebé emite carcajadas) y la narración prosigue: "Con algunos clics, él pasa a ser solamente digital. Con eso usted ahorra papel y colabora con un mundo más sustentable" (más papeles se rompen, más risas). "Use papel para lo que realmente vale la pena, cambie y cuente con Itaú para cambiar con usted."

Solo en la internet, el video fue visualizado casi 16 millones de veces ${ }^{8}$. Vale resaltar que el video original, con duración de 1 minuto y 43 segundos, tiene más de 96 millones de visualizaciones 9 . De hecho, una impresionante "adherencia" de contenido:

Las publicaciones on-line perciben cuáles artículos son más visualizados y cuáles prenden por más tiempo la atención de las personas. Las empresas de media evalúan cuáles videos son más vistos y por más tiempo. Tanto websites corporativos como los que no tienen fines lucrativos definen el éxito on-line en términos de tráfico en la web. [...] En suma, incluso más allá de

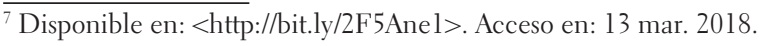

${ }^{8}$ Ver comercial del banco Itaú. Disponible en: <http://bit.ly/2RuCUV5>. Acceso en: 13 mar. 2018.

${ }^{9}$ Ver Baby laughing hysterically at ripping paper (original) disponible en: <http://bit.ly/2BVC9dZ>. Acceso en: 13 mar. 2018.
} 
los casos en que los acuerdos publicitarios se están trabajando por corredores, esa estrecha definición de "adherencia" ha brindado la lógica por medio de la cual se pasó a entender lo que es éxito" (JENKINS et al. 2014, p. 28).

Por fin, colocamos en análisis el ejemplo empírico A dramatic surprise on a quiet square; (una sorpresa dramática en una pacata plaza), un video con duración de 1 minuto y 45 segundos producido por la red de televisión por cable TNT. El video tiene inicio con la inserción de créditos como en las tradicionales películas hollywoodianas, con el siguiente texto: Somewhere in a little town in Belgium (En algún lugar de una pequeña ciudad en Bélgica), on a square where nothing really happens (en una plaza donde nada realmente sucede), we placed a button (Nosotros pusimos un botón). En el medio de la plaza hay un tótem con un botón rojo y una flecha donde se puede leer: push to add drama (presione para añadir drama) and waited for someone to push it (Se busca alguien para presionarlo). Las personas que caminan por la plaza demuestran extrañamiento; un ciclista pasa frente al tótem, mira desconfiado, pero resuelve apretar el botón rojo. A partir de entonces, una sirena toca anunciando una ambulancia llegando al local, paramédicos cargan un paciente en la camilla y lo dejan caer en el suelo, las personas se asombran, los paramédicos recogen el paciente y lo colocan en la ambulancia, olvidan las portas abiertas y cuando avanzan el paciente cae nuevamente. Un otro ciclista se distrae viendo al paciente en el piso y acaba por chocar en la puerta de la ambulancia. Como en las películas de aventura, el ciclista comienza a luchar con uno de los paramédicos y, simultáneamente, un vehículo policial persigue a un automóvil lleno de bandidos y, en el mismo lugar, sucede un tiroteo. Tras toda esta escenificación, un banner posicionado en lo alto de un edificio se abre y anuncia: Your daily dose of drama (su dosis diaria de drama) from 10/04 on telenet - TNT - we know drama. El video en cuestión tuvo más de 55 millones de visualizaciones ${ }^{10}$. En una combinación de escenificación de teatro con el lenguaje cinematográfico, el video promueve una entradilla para las películas de la red de una manera inusitada e inesperada. Al buscar interacción con el usuario, se hace con que las personas presentes en la plaza se sientan dentro de una película y esbocen reacciones de miedo, risa y sorpresa.

\footnotetext{
${ }^{10}$ Ver: a dramatic surprise on a quiet square. Disponible en: <http://bit.ly/2R5ruaN>. Acceso en: 13 mar. 2018.
} 


\section{Consideraciones finales}

Consideramos que experiencias como estas demuestran cómo la televisión está atenta a las nuevas formas de circulación de contenido y reconoce el papel fundamental que el espectador representa en ese proceso. De esta forma, compartimos la opinión de que:

Los profesionales de televisión y de audiovisual en general viven un momento de estupefacción, desafío y necesidades de riesgos en dirección a algo que aún no se sabe bien lo que podrá venir a ser. Vamos a vivir un periodo de mucha experimentación de nuevos modelos de televisión, donde algunos resultarán y otros probablemente fracasarán. Todo indica que estamos viviendo un fin de un modelo de televisión y el surgimiento de experiencias aun no muy nítidas, pero suficientemente expresivas para demandar investigación y análisis. (MACHADO; VÉLEZ, 2014, p. 56)

Pues, los lenguajes al chocarse y generar tensión potencializan los momentos de intraducibilidad y los tensionamientos pueden crear nuevos sentidos. Son los instantes en que el lenguaje asume la función creativa, según la Semiótica de la Cultura. Así como piensa Lotman (1999), durante eses procesos estamos produciendo semiosis y es cuando los códigos se desterritorializan y surge el nuevo (LOTMAN, 1999). En esa vía, esas piezas publicitarias exhibidas en la televisión presentan rupturas de sentidos, traen algún elemento que no concuerda con el sistema hegemónico (lo que es esperado), y ofrecen algo que nos pueden inquietar.

Ese movimiento solamente es posible, porque las fronteras son tenues y penetrables y están susceptibles a las intersecciones, que les aseguran su supervivencia y reconfiguración, como nos parecen los comerciales estudiados, ejemplos evidentes de cómo las fronteras entre los diferentes lenguajes del vasto sistema comunicacional de nuestros días se diluyen, sobreponen y se influencian. Eso es evidente cuando la media tradicional, la TV, reconoció el éxito del video casero y buscó aprovechar la "adherencia" de su contenido y de su alto potencial de "propagabilidad" en la internet, como en el comercial del Banco Itaú-Unibanco.

En los otros dos casos, el GP de Brasil de 2014 y la pieza de publicidad A dramatic surprise on la quiet square (una sorpresa dramática en una pacata plaza), hay también un alto potencial de "propagabilidad” y son muy importantes, porque pueden sobreponerse a las tradicionales técnicas y patrones de producción de la televisión. De ese modo, creemos que la internet transforma la manera de producir la publicidad al mismo tiempo se sobrepone a ella y la reconfigura en la era de la conexión. 
Actualmente, el escenario que se descortina carga características bien específicas que pasan por experiencias como los ejemplos empíricos anteriormente analizados, indicando un nuevo espectador más activo que reivindica cada vez más su espacio, sea como mero fan de una serie de ficción que comparte ideas con otros fans, sea como generador de contenidos amadores o profesionales que lanzan a la red producciones que, muchas veces sin ninguna pretensión, acaban por "pegar" y se propagar para mucho más allá de lo que se había sido planeado. De esta forma, las llamadas "nuevas medias", a través de sus plataformas como el YouTube, están permitiendo la exploración de nuevas posibilidades de producción de contenidos. No se trata solo de una convergencia meramente tecnológica entre los medios, sino, sobre todo, como pondera Jenkins (2009), de una profunda transformación cultural que permite a los usuarios compartir y buscar informaciones en medias diversas, diluyendo la antigua frontera entre productores y receptores de contenidos, así como las tenues fronteras entre lenguajes y sistemas culturales que divergen y se mezclan al mismo tiempo.

\section{Referencias}

CARLÓN. M.; FECHINE, Y. (Orgs). O fim da televisão. Rio de Janeiro: Confraria do Vento, 2014.

COCA, A. P.; SANTOS, A. T. "Formatos de ficção seriada televisual: tradições e perspectivas”. XXXVII Congresso brasileiro de Ciências da Comunicação. Comunicação: Guerra \& Paz. Anais [...]. Foz do Iguaçu: Itercom, 2014. Disponible en: <http://bit.ly/2Avxgbo> Acceso en: 13 mar. 2018.

FIDLER, R. Mediamorfosis. Barcelona: Granica, 1997.

JENKINS, H. Cultura da convergência. Trad. Susan Alexandria. 2. ed. São Paulo: Aleph, 2009.

et al. Cultura da Conexão. Trad. Patrícia Arnaud. São Paulo: Aleph, 2014.

LOPES, M. I. V.; OROZCO, G. (Coords). Relações de gênero nos países iberoamericanos - anuário Obitel 2015. São Paulo: Globo, 2015.

LOTMAN, I. M. Cultura y explosión - lo previsible y lo imprevisible en los procesos de cambio social. Barcelona: Gedisa, 1999.

La semiosfera I - semiótica de la cultura y del texto. Madrid: Cátedra, 1996. 
La semiosfera II - semiótica de la cultura, del texto e del espacio. Madrid: Cátedra, 1998.

. "Sobre el concepto contemporâneo de texto". Entretextos, Granada, n. 2, nov. 2003. Disponible em: <http://bit.ly/2BZCMmR>. Acceso en: 1 ago. 2014.

MACHADO, A. Arte e mídia. 3. ed. Rio de Janeiro: Jorge Zahar, 2010.

Pré-cinemas \& pós-cinemas. 6. ed. Campinas: Papirus, 2011.

; VÉLEZ, M. L. “Fim da Televisão?”. In: CARLÓN, M.; FECHINE, Y.

(Orgs). O fim da televisão. Rio de Janeiro: Confraria do Vento, 2014. p. 54-76.

MACHADO, I. "Experiências do espaço semiótico". Estudos de Religião, São Paulo, v. 29, n. 1, p.13-34, jan./jun. 2015.

MANOVICH, L. "Novas mídias como tecnologia e ideia: dez definições”. In: O chip e o caleidoscópio: reflexões sobre as novas mídias. São Paulo: Senac, 2005. p. 24-50.

OROZCO, G. “Televisão: causa e efeito de si mesma”. In: CARLÓN, M.; FECHINE, Y. (Orgs). O fim da televisão. Rio de Janeiro: Confraria do Vento, 2014. p. 96-113.

ROSÁRIO, N. M.; AGUIAR, L. M. “Implosão mediática: corporalidades nas configurações de sentidos da linguagem”. Significação, São Paulo, v. 41, n. 42, p. 166-185, 2014.

SANTAELLA, L. Cultura e artes do pós-humano: da cultura das mídias à cibercultura. São Paulo: Paulus, 2003.

A ecologia pluralista da comunicação: conectividade, mobilidade, ubiquidade. São Paulo: Paulus, 2010.

submetido em: 15 mar. 2018 | aprovado em: 18 jun. 2018 